\title{
Differences in the Experience and Expression of Sexual Jealousy: A Terror Management Theory Perspective
}

\author{
Claude H. Miller ${ }^{1}$, Bobi Ivanov ${ }^{2, *}$, Mark J. Landau ${ }^{3}$, Dini Masad ${ }^{4}$, Shane Semmler ${ }^{5}$, Jennifer Ann White ${ }^{6}$ \\ ${ }^{1}$ Department of Communication, University of Oklahoma, Norman, 02215, Oklahoma, United States \\ ${ }^{2}$ School of Journalism and Telecommunications, University of Kentucky, Lexington, 40506, Kentucky, United States \\ ${ }^{3}$ Department of Psychology, University of Kansas, Lawrence, 66045, Kansas, United States \\ ${ }^{4}$ Department of Marketing, University of Central Oklahoma, Edmond, 73034, Oklahoma, United States \\ ${ }^{5}$ Department of Communication Studies, University of South Dakota, Vermillion, 57069, South Dakota, United States \\ ${ }^{6}$ Department of Mass Communication, University of Central Oklahoma, Edmond, 73034, Oklahoma, United States \\ *Corresponding Author: bobi.ivanov@uky.edu
}

Copyright (C) 2014 Horizon Research Publishing All rights reserved.

\begin{abstract}
Although there is general agreement the causes and consequences of jealousy bear on self-esteem, research on the experience and expression of jealousy has produced conflicting results regarding gender differences. From the perspective of terror management theory TMT; 1], individuals adopt meaningful cultural worldviews-including culturally derived and expressed sexual attitudes - to strengthen their self-esteem and ward off existential anxiety. The present research assessed the idea that admitting vulnerability to feelings of sexual or emotional jealousy can pose a threat to self-esteem, thus altering how the emotion is expressed and communicated. Accordingly, we tested and found that men-generally thought to experience, exhibit, and express greater sexual jealousy than women - reported less sexual jealousy when mortality concerns were made salient. It is argued that gender differences in the expression of sexual jealousy (although not necessarily the experience) are moderated by self-esteem concerns associated with socialization and enculturation.
\end{abstract}

Keywords Anxiety, Death, Emotional Expression, Gender Differences, Jealousy, Self-Esteem, Sex

\section{Introduction}

Among human beings jealousy ranks distinctly as a weakness; a trademark of small minds ... a property which even the smallest is ashamed of. - Mark Twain2]

A competent and self-confident person is incapable of jealousy in anything. Jealousy is invariably a symptom of neurotic insecurity. - Robert Heinlein 3]

Although emotion theorists generally agree that jealousy, like many other emotions, is instrumental in ensuring reproductive fitness and strengthening interpersonal cohesion 4-11], there is also a widespread consensus as to its negative, destructive, and even fatal effects-particularly with regard to male sexual jealousy (see Harris12] for a detailed review). Thus, it is easy to appreciate Heinlein's 3] notion that jealousy, in its more severe forms, has consistently proven itself to be a telling indication of both an anxious lack of self-confidence, and an irrational fear of inadequacy.

Regarding sexual jealousy, there is little doubt that gender differences exist. An examination of the rates of divorce, spousal abuse, jealousy-related homicides, or the incidence of psychiatric cases of delusional or psychotic jealousy makes this point grimly clear 13-15]. Both sociocultural and evolutionary theorists seem to agree that male sexual jealousy is one of the primary instigators of violence across virtually all human cultures 12,16-19]. However, as noted above, nearly all emotions-including sexual jealousy - play important beneficial roles at the biological, individual, relational, and social levels 8].

Making sense of these conflictions is no mean feat, yet appreciating their nature is key to understanding the powerful competing motivations influencing the often contradictory character of emotional expression in general, and relational communication in particular. In this article we examine whether the expression of sexual jealousy may have harmful intrapsychic consequences for self-esteem. If, as Twain and Heinlein have suggested, feelings of jealousy undermine an individual's sense of security and self-worth, then people should be less likely to admit such feelings when self-esteem needs are heightened. We tested this prediction within the framework of terror management theory TMT; $1,20]$.

A great deal of communication research seems to be concerned more with addressing the "when," "where," and "how" of communication behavior than the "why." Rather than being explicitly addressed, the nature of motivation is often assumed or simply ignored in many communication theories. Instead of being theoretically explained (e.g., why are we motivated to reduce uncertainty? or, why do we make 
efforts to accommodate?), questions of motivation are often left as axiomatically assumed (we have a need to reduce uncertainty), or left to beg further questions (we accommodate because we have a need for affiliation). Rarely are overarching theories of motivation applied to explain human communication behavior at its most basic levels. The present research seeks to avoid this oversight by addressing an important aspect of communication behavior-i.e., gender differences in the experience and expression of jealousy - from the elemental, motivational perspective of TMT. While some people experience jealousy, but avoid its expression, others are motivated to express jealousy without actually experiencing it. Thus, to understand the complex nature of this emotion, and to appreciate its motivational impact on communication behavior, it seems useful to first examine its function from a biological as well as a social psychological standpoint.

\section{Sex and Gender Differences in Jealousy}

Examining romantic jealously, Parker21] found there were no significant differences between men and women when appraising a jealousy threat, and that the primary appraisal process (does this situation affect me?) dealing with jealousy appear to be similar for both men and women. However, the secondary appraisal process (is there anything I can do about it?) associated with coping behaviors and the expression of jealousy have not been fully explored with regard to sex or gender differences.

In studying the influence of sex and gender on jealousy experience, expression, and relational goals, Aylorand Dainton22] found that while men may tend to experience and express the more cognitive aspects of jealousy (e.g., with explicit thoughts about how to respond to threats by, for instance, restricting their partner's access to rivals), and use more distributive forms of communication, women were more likely to express the affective aspects (e.g., through emotional displays and rumination), and use more integrative forms of communication. Moreover, whereas masculinity was associated with antisocial responses to jealousy experiences (e.g., violence, confronting the rival, manipulation), femininity was associated with relatively more prosocial responses (e.g., self-enhancement, relational discussion, efforts to improve the relationship). Of particular interest to the present research, Aylor and Dainton22] found that, although sex was the stronger predictor of cognitive jealousy, gender was the stronger predictor of communicative responses to jealousy.

Since these findings suggest sex and gender play differing roles in the experience and expression of jealousy, it is important at the outset to draw a distinction between sex differences and gender differences. Whereas sex is consider to be inherited, physiological, hormonal, and phylogenetic, gender is conceived of as learned, sociological, psychological, and ontogenetic. While both sex and gender may each play a role and/or interact in the production and expression of jealousy, many communication scholars have failed to make any clear distinctions between the two constructs.

According to Buss and colleagues, because investing in another's offspring is costly, men are innately disposed to experience more distress than women over their mate's real or imagined sexual infidelity 4-6]. Whereas women, in contrast, are selected to be more concerned with mate retention and should thus experience more jealousy over their mate's romantic or emotional infidelity, since emotion involvement is so essential for a long-term relationships. In support of this notion, Buss et al.6] demonstrated men will report more distress when imagining a sexually unfaithful mate compared to an emotionally unfaithful mate, with the reverse being true for women. However, more recent evidence has cast doubt on the methodology used in these initial findings 23,24$]$, and it is not clear whether sex-typical jealousy is best characterized as an innate response, nor whether males are ineludibly more sexually jealous than females. More importantly, it is also not clear whether males will necessarily admit to feeling more jealous than females or be as likely to express their feelings of sexual jealousy. Our findings suggest there may be many instances when the reverse is actually the case-when the masculine psyche may deem it more expedient to conceal feelings of jealousy.

Terror management theory offers a framework for understanding the existential basis underlying gender-differentiated responses to sexual jealousy. In the pages that follow, we will proceed by presenting a brief overview of TMT explaining how individuals, in order to manage the anxiety associated with the inevitability of their mortality, adopt culturally derived sexual attitudes to strengthen their self-esteem. We then discuss how these received values may differentially impact the experience and expression of jealousy. We finish by offering and testing a set of TMT derived hypotheses concerning gender differences in the expression of emotional and sexual jealousy.

\section{Terror Management Theory}

Human beings, due to our great cognitive abilities, have a highly developed sense of self, which, when combined with our ability to comprehend the nature of temporality, gives us the power to extend our self-concepts into the future. Indeed, the fact that our awareness extends both backward and forward in time is a fundamental aspect of our human existence. Unfortunately, as TMT suggests, this awareness confronts us with the inescapable realization that we must one day parish from existence.

Following Kierkegaard25], Rank26], and Becker27] among others, TMT is based on the observation that our unique and undeniable awareness of death creates a potential for overwhelming existential anxiety (i.e., terror). Moreover, TMT posits such a distressing condition would be unmanageable were it not for our individual and collective senses of value and meaning. Consequently, in order to maintain our psychological equanimity, we humans must place our trust and confidence in a stable meaning-making system to help us maintain a secure conception of the self as 
an object of value within a meaningful existence. For this, we rely heavily on culture, and the worldviews we carefully build around it. Rank26] maintained that one's worldview develops primarily from an inner spiritual need for a sense of meaning beyond biological or social existence. Thus, the human cultural worldview (CWV) is "a continuous translation of supernatural conceptions into rational terms" conceived of as "an expression of the irrational self seeking material immortalization in lasting achievements" 26,p. 84].

By supplying us with a set of consensually held beliefs about the nature of reality, our CWV is capable of instilling our lives with meaning, order, significance, purpose, and above all, several forms of permanence. Moreover, according to TMT, our CWV sets the standards upon which our sense of self-esteem is based. Achieving success, or, conversely, failing to live up to one's culturally derived standards, has a direct and dynamic influence on self-esteem see 28,29 for reviews].

Because we humans are uniquely aware of the abstract notion that our lives will inevitably end one day, this realization engenders within us the potential for tremendous existential anxiety. Thus, as TMT posits, one's CWV and sense of self-esteem act together to buffer this ever-present potential for anxiety by managing our mortality concerns in two interrelated ways; 1) by allowing us to subscribe to cultural meaning systems instilling life with significance and value, while offering culturally sanctioned paths to symbolic and literal immortality, and 2) by maintaining the sustained perception that one is meeting or exceeding these culturally prescribed standards of value. In short, the perception of one's self as a valued member of a meaningful cultural reality is the basis of self-esteem, which in turn is the principal mechanism for allaying the existential anxiety associated with reminders of one's mortality.

Terror management theory posits that self-esteem is sought because it provides this protection against the fear of death 1,20$]$. Support for a terror management function of self-esteem is provided in part by tests of the anxiety buffer hypothesis, which states that, insofar as self-esteem provides protection from the potential for anxiety, then increased levels of self-esteem should reduce proneness to anxiety. In an initial test of this hypothesis, Greenberg et al. 30] found that boosting self-esteem with positive feedback on a personality or intelligence test reduced self-reported anxiety in response to graphic video depictions of death, and physiological arousal in anticipation of painful electric shocks see also 31,32]. Another line of support comes from tests of the mortality salience hypothesis, which posits that, insofar as self-esteem provides protection from mortality concerns, then temporarily increasing the accessibility of death-related thought (i.e., mortality salience-MS) should intensify efforts to bolster and defend self-esteem.

Multiple studies using diverse operationalizations of self-esteem defense have confirmed this broad hypothesis for a review, see 33]. For example, MS leads to increased efforts to fulfill contingencies of value and competence in valued domains, such as risky driving 34], fitness intentions 35], physical strength 36], charitable action 37], and identification with one's body 38] among those who value these domains as a source of self-esteem. Mortality salience has also been shown to increase other self-enhancing strategies, including adjustment of group identifications 39], and use of self-serving biases 40,41].

\section{Gender Differences in Self-Esteem}

Based on insights from TMT, Goldenberg et al.42] posited that sex differences in jealousy may reflect the differential bases of self-esteem people subscribe to in light of cultural roles and norms. More pertinent for our present purposes, Goldenberg et al.42] focused on the role of self-esteem in the experience of sexual and emotional jealousy, arguing that gender differences in sexual jealousy may stem in part from the disparity between men's and women's bases of self-esteem. Goldenberg et al. first demonstrated that women rated "being in a committed romantic relationship" as more important to their self-esteem than "having a good sex life," whereas men showed the opposite pattern. Using Buss et al.'s6] forced choice paradigm for assessing jealousy, they found that mortality salient men reported sexual infidelity to be more distressing relative to control-primed men, and that mortality salient women found emotional infidelity to be more distressing relative to control-primed women. These results suggest sex-typical jealousy responses are not only due to sex-specific imperatives - such as paternal uncertainty and mate retention - but also, in part, to the gender-specific self-esteem threats posed when the value one places in an important domain (such as sexual savvy or romantic attachment) is undermined by a partner's infidelity.

\section{The Present Study}

There may be a key difference, however, between experiencing a partner's emotional or sexual infidelity as distressing, and admitting to one's self that one is vulnerable to feelings of jealousy. Although jealous people are often seen as angry and vengeful 43], they might also be viewed as depressed and dejected souls, seeking comfort and protection from anxiety, self-doubt, loss of face, and fear at the prospect of their own inadequacy 44], as reflected in the above quotes by Twain and Heinlein. Freud44] viewed jealousy in a similar light, referring to so-called "normal" jealousy (as opposed to pathological or morbid jealousy) as:

Compounded of grief, the pain caused by the thought of losing the loved object, and of the narcissistic wound further, of feelings of enmity against the successful rival, and of a greater or lesser amount of self-criticism which tries to hold the subject's own ego accountable for his loss. p. 223]

In keeping with this notion, research has consistently found a negative relationship between self-esteem and various forms of jealousy 45-51, but see 52], and men in particular may often cope with jealousy by using denial and avoidance 53]. Thus, since the outward expression of an emotion may not always reflect the inward experience, further study of how people respond in various potentially jealousy inducing situations is warranted. 
The present study aims to directly test the potential self-esteem threats posed by sexual and emotional jealousy, and examine how they may influence responses to a self-report jealousy measure. Specifically, insofar as men might be expected to invest more self-esteem in their perceived sexual prowess, they should also be less likely to feel comfortable admitting to themselves such feelings of jealousy, and this effect should be enhanced when mortality is salient. Likewise, insofar as women invest more self-esteem in emotional commitment, we might expect MS to increase women's discomfort in admitting emotional jealousy. These predictions seem contrary to those tested by Goldenberg et al.42]; however, those studies used Buss et al.'s6] forced choice paradigm whereby participants were asked to decide whether their partner's emotional versus sexual infidelity would be more distressing. They were not given the option of expressing or denying their own need for jealous feelings.

The present study, in contrast, uses a self-report measure of feelings of jealousy 54] employing a continuous rating scale. By allowing participants to admit to or deny jealous feelings, we sought to test the idea that, in self-esteem relevant domains, admitting one's vulnerability to jealousy can in itself pose a threat to self-esteem, and thus inhibit the expression of this emotion.

Based on the foregoing analysis, we made the following hypotheses. First, regarding women, when self-esteem needs are not heightened by MS, we expect the sex difference found by Buss et al.6] as predicted by an evolution-based account:

H1: There is a main effect for sex on self-reported emotional jealousy, whereby females will report higher levels of emotional jealousy relative to males.

On the other hand, MS is expected to heighten the feminine self-esteem needs of women, overriding sex-typical jealousy responses, thus we predict:

$\mathrm{H} 2$ : There is a simple effect involving gender and priming condition, such that women will self-report lower levels of emotional jealousy following the MS prime relative to women in the control condition.

With regard to men, when self-esteem needs are not at issue, consistent with Buss et al.'s6] evolution-based perspective, we predict:

H3: There is a main effect for sex on self-reported sexual jealousy, whereby males will report higher levels of sexual jealousy relative to females.

Because the expression of jealousy may in part be a function of context-induced variability in self-evaluation 55], and men may often cope with jealousy by using denial and avoidance 53], for men, the heighten self-esteem needs related to $\mathrm{MS}$ is expected to override sex-typical jealousy responses, therefore we predict:

H4: There is a simple effect involving gender and priming condition, such that men will self-report lower levels of sexual jealousy following the MS prime relative to men in the control condition.

\section{Method}

\subsection{Participants}

A total of 224 undergraduates (161 women, $63 \mathrm{men}$ ), mean age $=20.02, \mathrm{SD}=1.82$, participated in exchange for extra course credit at a large U.S. university. Roughly 5\% identified themselves as African American, 7\% Asian, 75\% Caucasian, 5\% Hispanic, 5\% Native American, and 3\% other. About half of the sample were recruited from introductory classes (mostly general education students), and half from advanced classes (mostly communication majors). The demographic profile of this sample is representative of the university as a whole.

\subsection{Materials and Procedure}

This study utilized a 2 (priming condition: MS/control) x 2 Sex: male/female) between subjects design. In a classroom setting, participants were asked to complete a packet of questionnaires described as a "motivation study." All packets were identical in content except for the MS v. control manipulations.

\subsubsection{Mortality Salience}

For those in the mortality salient condition, MS was manipulated by having participants provide responses to a 14-item subscale based on the Orientation Towards Dying and Death Inventory OTDDI, 56] containing items referring to the morbid, objective, and finite aspects of death, after which they read a one page essay on the fearful, traumatic, and creaturely aspects of death, followed by two items asking how "reasonable" and "credible" they thought the passage was, and whether they had ever thought of the issues in that way before.

In the control condition participants provided responses to items referring to either spiritual and inspirational issues, or scholastic practices, along with a one page essay on various aspects of spirituality, or exam taking, ${ }^{1}$ followed by the same two follow-up items mentioned above, asking how "reasonable" and "credible" the passage was, and whether participants had thought about these issues in a similar way before. Participants in both the MS and control prime conditions were then presented with the PANAS-X 57], a 25-item self-report mood scale, provided primarily as a delay and distraction, but also useful in assessing the prime conditions for variations in mood. After the PANAS-X (time permitting) they were instructed to read a short literary passage serving as further delay and distraction, and asked to judge whether they thought the author of the passage was male or female. Participants' death thought accessibility was assessed roughly six to seven minutes following the prime

\footnotetext{
1 Two control scenarios were included as a part of a separate study examining the effects of specific characteristics of death salience on terror management defenses. Since there were no significant differences on any of the dependent measures between the two control conditions, they were collapsed into a single control condition.
} 
manipulation.

\subsubsection{Manipulation Check}

Participants in both conditions were given a manipulation check consisting of a word stem completion task used in previous TMT research e.g., 58] designed to assess the accessibility of death-related themes. The measure consisted of 26 word fragments participants were instructed to complete with the first word coming to mind. Eight of the 26 fragments can be completed with either a neutral or death-related word. For example, the fragment $\mathrm{COFF}_{-}$can be completed as COFFEE (a neutral word) or COFFIN (a death-related word). The possible death-related words were buried, skull, dead, stiff, coffin, corpse, and grave.

\subsubsection{Self-Report Jealousy Scale}

Thoughts related to jealousy were assessed using Bringle et al.'s54] Self-Report Jealousy Scale (SRJS), which is composed of 24 Likert-type items involving a series of brief vignettes (e.g., You have just discovered your partner is having an affair with someone at work) followed by response options regarding how one might feel about them measured on a 5-point scale, anchored by $0=$ Pleased, and $4=$ Extremely upset. Previous research using the SRJS has identified differing underlying factors, which Bringle et al. have subdivided into sexual, social, work, and family subscales. Gehl and Watson59] used factor analysis to define a 3-factor structure which included envy, infidelity reaction, and commitment threat. To identify the nature of the common factors underlying the SRJS in the present study, the 24 items were entered into an exploratory factor analysis using Maximum Likelihood extraction, followed by Promax rotation with Kaiser Normalization. This revealed a three factor solution closely corresponding to Gehl and Watson's59] results.

We found 11 items loading on an emotional jealousy factor (corresponding to Gehl \& Watson's commitment threat). Sample items include: Your partner flirts with someone else; Your partner suddenly shows an interest in going to a party when s/he finds out that someone will be there with whom s/he has been romantically involved with previously; and, Someone flirts with your partner. Scores on these items were averaged to form a composite emotional jealousy score (11-item $\alpha=.84$; actual scores ranged from .10 to 3.8 ).

We found 4 items loading on a sexual jealousy factor (corresponding to Gehl\& Watson's infidelity reaction). Sample items include: Your partner has sexual relations with someone else. You have just discovered your partner is having an affair with someone at work; and, At a party, your partner kisses someone you do not know. Scores on these items were similarly averaged to form a sexual jealousy composite (4-item $\alpha=.75$; actual scores ranged from 1.0 to 4.0).

Finally, although this third subscale was not used in the present study, we found 9 items loading on what we refer to as a social jealousy/envy factor (corresponding to Gehl \&
Watson's envy). Sample items included: The group to which you belong appears to be leaving you out of plans, activities, etc.; While at a social gathering of a group of friends, your partner spends little time talking to you, but engages the others in animated conversation. (9-item $\alpha=.81$; actual scores ranged from 1.0 to 4.0).

Following the SRJS, participants were debriefed and excused.

\section{Results}

\subsection{Manipulation Checks}

Arndt, Cook, and Routledge60] have demonstrated that distal terror management defenses, which serve in part to defend self-esteem, are elicited by the heightened accessibility of death related thoughts following a delay and distraction when death related thoughts are accessible but no longer within conscious focal awareness. To evaluate this, we conducted a t-test to compare the number of death-related word fragment completions within the MS and control conditions. Results revealed a significant main effect for prime, $\mathrm{t}(217)=2.10, \mathrm{p}<025, \mathrm{~d}=.34$, revealing greater death-thought accessibility among participants in the MS condition $(\mathrm{M}=2.63, \mathrm{SD}=1.22)$ relative to those in the control condition, $(\mathrm{M}=2.14, \mathrm{SD}=1.17)$. Consistent with Arndt et al.61], this result indicates an increase in death thought accessibility following the MS induction.

\subsubsection{Mood}

To test whether prime condition had an effect on mood, we performed t-tests on the general positive and negative affect subscales of the PANAS-X, and found no significant differences, $\mathrm{t}(217)=1.32$, n.s., and $\mathrm{t}(217)=1.16$, n.s., respectively. Consistent with past TMT research, there were no apparent differences in mood between the MS and control conditions.

\subsection{Multivariate Analysis}

A 2-prime (MS/control) x 2-sex (male/female) MANOVA with emotional and sexual jealousy serving as the dependent variables yielded significant main effects for both sex, $\mathrm{F}(2$, $215)=16.35, \mathrm{p}<.001$, and prime, $\mathrm{F}(2,215)=6.86, \mathrm{p}<.01$, and these effects were qualified by a significant interaction between prime and sex, $\mathrm{F}(2,215)=4.77, \mathrm{p}<.01 .^{2}$ To interpret this interaction, we performed separate ANOVAs on emotional and sexual jealousy.

${ }^{2} \mathrm{We}$ also tested for a prime $\mathrm{x}$ delay $\left.\mathrm{F}(2,215)=8.75, \mathrm{p}<.001\right]$ interaction to assess the effects of immediate versus delayed exposure to the dependent measures. However, this issue is tangential to the present study, and so will not be discussed here. 


\subsubsection{Emotional Jealousy}

The univariate analyses revealed a significant main effect for sex on emotional jealousy in the direction hypothesized by $\mathrm{H} 1$, with women reporting greater levels of emotional jealousy $(\mathrm{M}=2.29, \mathrm{SD}=.72)$ than men $(\mathrm{M}=1.83, \mathrm{SD}$ $=.68), F(1,216)=11.88, p<.01$, (see Figure 1). Since this effect was not qualified by the hypothesized simple effect of prime on women for emotional jealousy, $\mathrm{H} 2$ was not supported.

Main effect of Sex on Emotional Jealousy

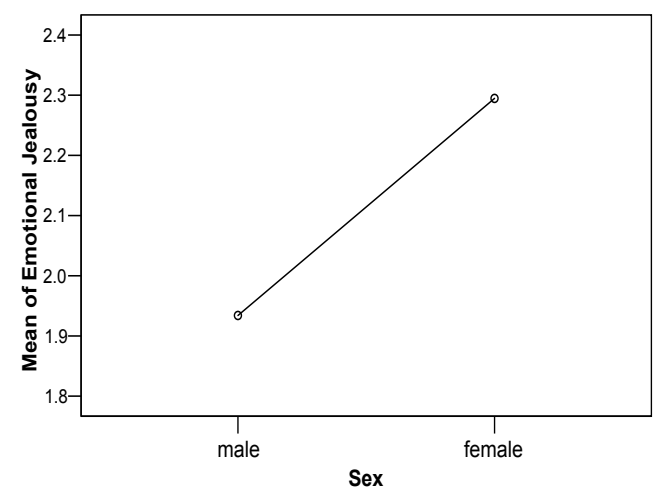

Figure 1. Main effect Sex on Emotional Jealousy

\subsubsection{Sexual Jealousy}

The univariate analyses revealed a significant main effect for sex on sexual jealousy, although it was in the opposite direction predicted by $\mathrm{H} 3$ : men actually reported less sexual jealousy $(\mathrm{M}=3.55, \mathrm{SD}=.60)$ than women $(\mathrm{M}=3.88, \mathrm{SD}$ $=.25), \mathrm{F}(1,216)=30.56, \mathrm{p}<.001$.

However, this main effect was qualified by an interaction involving sex and prime, $\mathrm{F}(1216)=5.28, \mathrm{p}<.05$, and pairwise comparisons examining the simple effects of prime on each sex indicated no significant difference for women, $\mathrm{t}$ $(77)<1.00$, n.s. However, in support of $\mathrm{H} 4$, men in the MS condition reported less sexual jealousy $(\mathrm{M}=2.95, \mathrm{SD}=1.16)$ than men in the control condition $(\mathrm{M}=3.70, \mathrm{SD}=.42), \mathrm{t}(32)$ $=2.77, \mathrm{p}<.01$, indicating the main effect for prime on sexual jealousy was entirely a function of the males' responses to the SRJS sexual jealousy subscale in the MS condition (see Figure 2).

Sex by Condition interaction on Sexual Jealousy

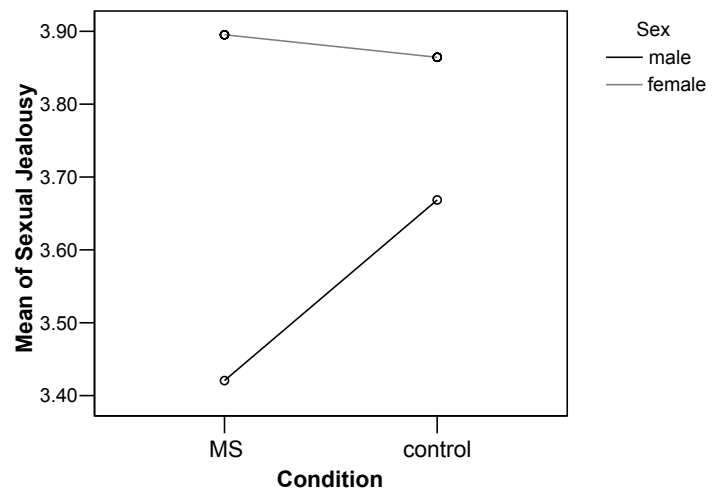

Figure 2. Sex by Condition interaction on Sexual Jealousy

\section{Discussion}

Previous TMT research has demonstrated that because self-esteem functions as a buffer against mortality concerns 33],mortality salience will lead people to make cognitive and behavioral efforts to maintain or enhance their self-esteem in culturally 29] and personally relevant domains 62]. Based on this reasoning, Goldenberg et al.42] proposed that sex differences in sexual and emotional jealousy may be due in part to gender differences in bases of self-esteem - with men placing greater value on the sexual aspects of relationships, and women on the romantic aspects. Goldenberg and colleagues demonstrated that MS can lead men to report more distress over their mate's imagined sexual infidelity, and lead women to report more distress over their mate's imagined romantic infidelity. Extending this work, the present research tested the idea that, within one's gender-valued domain, admitting feelings of jealousy to one's self can, by signaling insecurity or inadequacy, engender greater existential anxiety in and of itself.

From an evolution-based perspective, we anticipated that, overall, women would report higher levels of emotional jealousy relative to men, and this hypothesis was supported. However, contrary to our expectations based on TMT, we did not find women responding to MS by self-reporting less emotional jealousy. Thus, it would seem admitting one is vulnerable to feelings of romantic jealousy may not have much of an effect on women's experience of existential anxiety. Although men are not "supposed" to be emotional nor take pride in their ability to foster and maintain romantic relationships, we anticipated that women, seeing themselves as more nurturing and skilled in this regard, would be more vested in terms of these presumably more valued aspects of a feminine self-concept. However, based on the findings reported here, this does not appear to be the case.

Similarly, from an evolution-based perspective 4,5], we anticipated men would report higher levels of sexual jealousy then women. However, this hypothesis was not supported; men actually expressed significantly lower levels of sexual jealousy in all conditions. Nevertheless, in keeping with TMT, when primed with MS, men self-reported significantly lower levels of sexual jealousy than their counterparts in the control condition. These findings suggest an evolution-based account alone may be inadequate to explain men's expression of sexual jealousy, particularly if self-esteem issues are made salient. Moreover, conceding to one's self that one is vulnerable to feelings of sexual jealousy, in itself, may pose a threat to masculine self-esteem. Why might an evolution-based perspective appear to offer a better account of the expression of emotional jealousy among women, whereas a TMT-based perspective offers a better account of the expression of sexual jealousy among men?

\subsection{Sexual and Emotional Jealousy and Self-Esteem}

No doubt, sexual jealousy is threatening to both men and women. However, men may be more susceptible to the threat 
simply because they experience sexual jealousy more often or more intensely 63]. Men are, in a sense, enculturated to be Don Juans, whereas in contrast, women are admonished not to be Jezebels 64]. While the dominant CWV in the West tends to encourage men to seek multiple partners and take pride in their machismo, it generally and traditionally has discouraged women from indulging in sexual adventure. Sexual jealousy in men has been negatively correlated with self-esteem 50,51,65], moreover, previous research has found men may often cope with jealousy by using denial and avoidance 53], and the expression of jealousy may in part be a function of context-induced variability in self-evaluation 55]. Thus, if men are prone to base their self-esteem on sexual savvy, they should be more reluctant to admit to sexual jealousy-seeing it as a proxy for sexual inadequacy — when they are made to be implicitly sensitive to their own esteem needs. For this reason, we expected MS effects on the expression of sexual jealousy among men but not among women, and this prediction was supported.

On the other hand, we expected MS effects on emotional jealousy among women but not men, because, as Buss and colleagues have theorized, and as Goldenberg and colleagues have found, women appear to place more value on emotional commitment than do men 4-6,42,66]. The present findings suggest however, that although women may value emotional commitment, emotionality, as such, emotionality may not be as esteem-relevant for women as machismo may be for men.

The results reported here suggest sexuality and emotionality, because they are differentially related to self-esteem, may also be differentially related to the expression of jealousy in men and women. Although fear for the security of a relationship can generate anxiety, its focus may be more on the relationship, rather than on the self. Another possibility is that sexuality is more of a performance domain, where one seeks to secure a quantity of quality mates; whereas, in contrast, emotionality may not be so perceived - in the sense that one is less likely to take pride in securing emotional connections. If emotional jealousy is less apt to serve as an indication that one has performed inadequately, it should pose less of a threat to self-esteem than should sexual jealousy. Moreover, due to emotionality being perceived as a potential vulnerability for women - as opposed to sexual machismo being perceived as a decided strength for men-women should perhaps be even less inclined to perceive emotional jealousy as a threat to self-esteem.

Although placing greater value on the sexual aspects of close intimate relationships may encourage men to anticipate greater distress as a result of sexual infidelity, admitting to one's self that one may in fact be vulnerable on this front could pose an even greater threat to self-esteem. Thus, evolved psychological mechanisms may be interacting with culturally received values. In terms of sexual jealousy, evolutionary processes related to parental uncertainty may be the basis for males experiencing greater distress, however enculturation processes related to self-esteem issues may be the basis for men wanting to think of themselves as being less sexually jealous, thus rendering them more reluctant to express their sexual jealousy to others, or even admit it to themselves. Moreover, Landau et al.66] found that, although males generally evaluate sexually attractive members of the opposite sex more positively than females do, this sex difference tends to disappear following MS, when males - but not females - actually tend to derogate sexually attractive members of the opposite sex.

Support for $\mathrm{H} 1$ and the finding that women self-reported more emotional jealousy than men, appears to bolster Buss and colleagues' evolution-based view that, due to mate retention imperatives, women should respond with greater levels of emotional jealousy than men 4-6]. However, Harris67] offers a social-cognitive theory of jealousy based on appraisal theory 68-70], which emphasizes the interpretation of threats associated with the instigation of various forms of jealousy. Particularly pertinent to emotional and sexual jealousy are perceptions indicating that a rival (real or imagined) poses a threat to the self-relevant resources (both physical and psychological) one has invested in an intimate relationship. By this account, the type of jealousy one experiences, whether sexual or emotional, is determined by the esteem-relevant aspects upon which one focuses.

Harris71] argues that both men and women-particularly women who have sexual experience-tend to focus more on sexual infidelity relative to emotional infidelity. Likewise, Shackelford et al.72], using forced-choice dilemmas, found that older women were less likely than younger women to select a partner's emotional infidelity as more distressing than a partner's sexual infidelity. This fits with Harris'71] position if one assumes older women are likely to be more sexually experienced than younger women.

When sexual and emotional infidelity scenarios are presented separately, and jealousy is assessed using continuous rating scales rather than forced-choice measures, Harris71] notes that the expected sex differences tend to disappear or even shift in the opposite direction-with women reporting stronger reactions to sexual jealousy than men. In the present study, we used a continuous rating scale; however, sexual and emotional infidelity scenarios were presented together rather than separately, and women were found to self-report greater levels of both romantic and sexual jealousy.

In examining the data relevant to sexual jealousy, the main effect for priming condition can be accounted for entirely by the men's responses. Whereas MS had no effect on women's responses to the SRJS, men in the MS condition expressed significantly lower levels of sexual jealousy (nearly one full point on a 4-point scale) relative to men in the control condition.

Clearly, romantic relationships have an impact on self-esteem, and it follows that placing differing emphases on differing aspects of romantic relationships should produce differential influences on the kinds of jealousy people will self-report 73]. Although men may be innately predisposed to experience sexual jealousy, it appears that feeling, 
confronting, and expressing the emotion can nevertheless threaten their sense of adequacy. Moreover, Kosloff, Greenberg, Sullivan, and Weise 74] found that, although men in an uncertainty salient control condition found a sexually available short-term dating prospect more sexually attractive, those perceptions of attractiveness were significantly reduced among males in the MS condition. In support of Landau et al.66], Kosloff et al.74] concluded MS reduces men's preference for female sexual availability in favor of less esteem-related concerns associated with more worldview relevant values. Taken together, these findings may help to explain the tendency for males to express less rather than more sexually jealousy when their mortality is made salient.

\subsection{Implications for TMT and Future Directions}

Whereas a number of TMT studies have focused on how MS may enhance striving within self-esteem relevant domains see 33], the present study focuses more explicitly on how expressing an emotional state like jealousy might reflect poorly on the self, suggesting that, at least for men, self-esteem needs rooted in existential concerns may inhibit the expression of jealousy. Given the potentially destructive and even lethal effects of sexual jealousy alluded to at the outset of this paper, this may be a beneficial effect. However, this effect suggests existentially-rooted self-esteem needs may also inhibit open communication of jealous feelings, and undermine the cohesiveness of romantic relationships.

Although the implications of this study for sex and gender differences in the experience and expression of jealousy may be provocative, they are preliminary, and more research is needed to flesh out the complex social cognitive nuances involved. And although self-esteem must certainly play a key role in the experience and expression of jealousy, the present research did not directly manipulate nor measure self-esteem. Furthermore, while we refer to gender differences throughout this paper, we have used sex as a proxy for gender in the analyses. Future research should include both self-esteem and gender assessments, and measures designed to differentiate between the masculine and feminine bases of self-esteem.

Nonetheless, the present research suggests people-particularly men-can exhibit ambivalence concerning the experience and expression of sexual jealousy, which may stem in part from existentially rooted, genderand esteem-relevant concerns. This finding is consistent with previous TMT research indicating that for men, despite the stereotypes, sex may not always be an approach behavior. Goldenberg and colleagues42,75] have shown that thinking about sex can prime thoughts about death, and conversely, men primed with MS tend to distance themselves from the physical - but not the spiritual or emotional - aspects of sex. It should be noted that in the present study, it was only when the creaturely aspects of death were primed that males expressed less sexual jealousy.

Landau et al.66] demonstrated that men will respond to
MS by denying their attraction to sexually provocative women. They also showed how making both death and one's susceptibility to sexual provocations salient can increase men's tolerance for aggression against women. Conversely, Kosloff et al.74] found that, in the context of short-term romantic relationships, MS induced self-esteem striving can motivate greater interest in physically attractive members of the opposite sex, whereas in the context of long-term romantic relationships, MS tends to motivate less concern with physical attractiveness and more concern for dating a partner who shares one's religious and worldview validating values. The present findings would seem to confirm this conclusion if one assumes college-aged males are likely to be relatively more concerned with short-term versus long-term relationships.

In short, TMT provides empirically substantiated insights into how concerns about the body and self-esteem can generate ambivalence in connection with human interaction, sexuality, courtship, and mate selection. The current study contributes to this research by demonstrating how gender-relevant self-conceptions can moderate the expression of sexual jealousy-an emotion with important social and interpersonal consequences. Further exploration into this area may help explain how and why people's implicit emotional experiences may sometimes be contradicted by their explicit emotional expressions, and thus not always coincide with expected communication behaviors.

\section{REFERENCES}

[1] J. Greenberg, T. Pyszczynski, S. Solomon. The causes and consequences of a need for self-esteem: A terror management theory. In R. F. Baumeister, Public Self and Private Self, Springer-Verlag, New York, 189-212, 1986.

[2] M. Twain. Letters from the Earth, Harper \& Row, New York, 1909/1962.

[3] R. A. Heinlein. Time Enough for Love: The lives of Lazarus Long. Putnam, New York, 1973.

[4] D. M. Buss. The strategies of human mating, American Scientist, Vol.82, No.3, 238-249, 1994.

[5] D. M. Buss. Psychological sex differences: Origins through sexual selection, American Psychologist, Vol.50, No.3, 164-168, 1995.

[6] D. M. Buss, R. J. Larsen, D. Westen, J. Sex differences in jealousy: Evolution, physiology, and psychology, Psychological Science, Vol.3, No.4, 251-255, 1992.

[7] R. H. Frank. Passions within Reason: The Strategic Role of the Emotions, Norton, New York, 1988.

[8] L. K. Guerrero, P. A. Anderson. Jealousy experience and expression in romantic relationships. In P. A. Andersen and L. K. Guerrero, Handbook of Communication and Emotion, Academic, Sand Diego, 156-183, 1998 
[9] C. E. Izard. Basic emotions, relations among emotions, and emotion-cognition relations, Psychological Review, Vol.99, No.3, 561-565, 1992.

[10] R. S. Lazarus. Jealousy. In R. S. Lazarus, B. N. Lazarus, Passion and Reason: Making Sense of Our Emotions, Oxford, New York, 34-40, 1994.

[11] P. Salovey, A. Rothman. Envy and jealousy: Self and society. In P. Salovey, The Psychology of Jealousy and Envy, Guilford, New York, 271-286, 1991.

[12] C. R. Harris. A review of sex differences in sexual jealousy, including self-report data, psychophysiological responses, interpersonal violence, and morbid jealousy, Personality and Social Psychology Review, Vol.7, No.2, 102-128, 2003.

[13] M. Daly, M. Wilson. Homicide, Aldine, New York, 1988.

[14] M. Daly, M. Wilson, S. J. Weghorst. Male sexual jealousy, Ethology and Sociobiology, Vol.3, No.1, 11-27, 1982.

[15] M. Soyka. Prevalence of delusional jealousy in schizophrenia, Psychopathology, Vol.28, No.2, 118-120, 1995.

[16] D. M. Buss. The Dangerous Passion: Why Jealousy is as Necessary as Love and Sex, The Free Press, New York, 2000.

[17] L. K. Guerrero, P. A. Anderson. The dark side of jealousy and envy: Desire, delusions, desperation, and destructive communication. In B. H. Spitzberg, W. R. Cupach, The Dark Side of Close Relationships, Erlbaum, Mahwah, NJ, 33-70, 1998.

[18] S. Pinker. How the Mind Works, Norton, New York, 1997.

[19] M. Wilson, M. Daly. The man who mistook his wife for a chattel. In J. Barkow, L. Cosmides, J. Tooby, The Adapted Mind: Evolutionary Psychology and the Generation of Culture, Oxford, U.K.: Oxford, Oxford, UK, 289-322, 1992.

[20] S. Solomon, J. Greenberg, T. Pyszczynski. A terror management theory of social behavior: The psychological functions of self-esteem and cultural worldviews. In M. Zanna, Advances in Experimental Social Psychology, Academic, Sand Diego, Vol.24, 91-159, 1991.

[21] R. G. Parker. The influence of sexual infidelity, verbal intimacy, and gender upon primary appraisal processes in romantic jealousy, Women's Studies in Communication, Vol.20, No.1, 1-24, 1997.

[22] B. Aylor, M. Dainton. Antecedents in romantic jealousy experience, expression and goals, Western Journal of Communication, Vol.65, No.4, 370-391, 2001.

[23] D. A. DeSteno, M. Bartlett, J. Braverman, J., P. Salovey. Sex differences in jealousy: Evolutionary mechanism or artifact of measurement?, Journal of Personality \& Social Psychology, Vol.83, No.5, 1103-1116, 2002.

[24] D. A. DeSteno, P. Salovey. Evolutionary origins of sex differences in jealousy? Questioning the "fitness" of the model, Psychological Science, Vol.7, No.6, 367-372.

[25] S. Kierkegaard. Fear and Trembling and The Sickness unto Death. Princeton University Press, Princeton, NJ, 1849/1954.

[26] O. Rank. Beyond Psychology, Dover, 1941.

[27] E. Becker. The Denial of Death, The Free Press, New York, 1973.
[28] J. Greenberg, S. L. Koole, T. Pyszczynski. Handbook of Experimental Existential Psychology, Guilford, New York, 2004.

[29] J. Greenberg, S. Solomon, T. Pyszczynski. Terror management theory of self-esteem and cultural worldviews: Empirical assessments and conceptual refinements. In M. Zanna, Advances in Experimental Social Psychology, Academic, New York, Vol.29, 61-139, 1997.

[30] J. Greenberg, S. Solomon, T. Pyszczynski, A. Rosenblatt, J. Burling, D. Lyon, E. Pinel, L. Simon. Assessing the terror management analysis of self-esteem: Converging evidence of an anxiety-buffering function. Journal of Personality and Social Psychology, Vol. 63, No.6, 913-922, 1992.

[31] J. Greenberg, T. Pyszczynski, S. Solomon, E. Pinel, L. Simon, K. Jordan. Effects of self-esteem on vulnerability-denying defensive distortions: Further evidence of an anxiety-buffering function of self-esteem, Journal of Experimental Social Psychology, Vol.29, No.3, 229-251, 1993.

[32] E. Harmon-Jones, L. Simon, J. Greenberg, T. Pyszczynski, S. Solomon, H. McGregor. Terror management theory and self-esteem: Evidence that increased self-esteem reduces mortality salience effects, Journal of Personality and Social Psychology, Vol.72, No.1, 24-36, 1997.

[33] T. Pyszczynski, J. Greenberg, S. Solomon, J. Arndt, J. Schimel. Why do people need self-esteem?: A theoretical and empirical review, Psychological Bulletin, Vol.130, No.3, 435-468, 2004.

[34] O. Taubman-Ben-Ari, V. Florian, M. Mikulincer. Does a threat appeal moderate reckless driving? A terror management theory perspective, Accident Analysis and Prevention, Vol.32, No. 1, 1-10, 2000.

[35] J. Arndt, J. Schimel, J. L Goldenberg. Death can be good for your health: Fitness intentions as a proximal and distal defense against mortality salience, Journal of Applied Social Psychology, Vol.33, No.8, 1726-1746, 2003.

[36] H. J. Peters, J. Greenberg, J. M. Williams, N. R. Schneider. Applying terror management theory to performance: Can reminding individuals of their mortality increase strength output?, Journal of Sport \& Exercise Psychology, Vol.27, No.1, 111-116, 2005.

[37] E. Jonas, J. Schimel, J. Greenberg, T Pyszczynski. The Scrooge Effect: Evidence that mortality salience increases prosocial attitudes and behavior, Personality and Social Psychology Bulletin, Vol.28, No.10, 1342-1353, 2002.

[38] J. L. Goldenberg, T. Pyszczynski, K. D. Johnson, J. Greenberg, S. Solomon. Fleeing the body: A terror management perspective on the problem of human corporeality, Personality and Social Psychology Review, Vol.4, No.3, 200-218, 2000.

[39] M. Dechesne, J. Greenberg, J. Arndt, J. Schimel. Terror management and sports fan affiliation: The effects of mortality salience on fan identification and optimism, European Journal of Social Psychology, Vol.30, No.6, $813-835,2000$

[40] M. Dechesne, T. Pyszczynski, J. Arndt, S. Ransom, K. M. Sheldon, A. van Knippenberg, J. Janssen. Literal and symbolic immortality: The effect of evidence of literal immortality on self-esteem striving in response to mortality 
salience, Journal of Personality and Social Psychology, Vol.84, No.4, 722-737, 2003.

[41] M. Mikulincer, V. Florian, V. The effect of mortality salience on self-serving attributions-evidence for the function of self-esteem as a terror management mechanism, Basic and Applied Social Psychology, Vol.24, No.4, 261-271, 2002.

[42] J. Goldenberg, M. J. Landau, T. Pyszczynski, C. R. Cox, J. Greenberg, S. Solomon, H. Dunnam. Gender-typical responses to sexual and emotional infidelity as a function of mortality salience induced self-esteem striving, Personality and Social Psychology Bulletin, Vol.29, No.12, 1585-1595, 2003.

[43] R. S. Lazarus. Stress and Emotion: A New Synthesis, Springer, New York, 1999.

[44] S. Freud. Some Neurotic Mechanisms in Jealousy, Paranoia and Homosexuality, Standard Edition, XVIII, Hogarth, London, 1922.

[45] R. G. Bringle. Psychosocial aspects of jealousy: A transactional mode. In P. Salovey, The Psychology of Jealousy and Envy, Guilford, New York, 1991.

[46] B. Buunk. Anticipated sexual jealousy: Its relationship to self-esteem, dependency and reciprocity, Personality \& Social Psychology Bulletin, Vol.8, No.2, 310-316, 1982.

[47] B. Buunk. Husbands jealousy. In R. A. Lewis, R. E. Salt, Men in Families, Sage, Beverly Hills, CA, 97-114, 1986.

[48] G. Clanton. Jealousy and envy. In J. E. Stets, J. H. Turner, Handbook of the Sociology of Emotions, Springer, Berlin, 410-442, 2006.

[49] J. L. Francis. Toward the management of heterosexual jealousy, Journal of Marriage \& Family Counseling, Vol.3, No.4, 61-69, 1977.

[50] E. W. Mathes, H. E. Adams, R. M. Davies. Jealousy: Loss of relationship rewards, loss of self-esteem, depression, anxiety, and anger, Journal of Personality \& Social Psychology, Vol.48, No.6, 1552-1561, 1985.

[51] R. A. Stewart, M. J. Beatty. Jealousy and self-esteem, Perceptual \& Motor Skills, Vol.60, No.1, 153-154, 1985.

[52] D. D. Bohn, M. E. Preul, W. Dragon. Romantic Jealousy and Self-Esteem: Subscales Reveal a Positive Relationship. Paper presented at the American Psychology Society Convention, San Francisco, 1996

[53] P. E. Mullen, J. Martin. Jealousy: a community study, British Journal of Psychiatry, Vol.164, No.1, 35-43, 1994.

[54] R. G. Bringle, S. Roach, C. Andier, S. Evenbeck. Measuring the intensity of jealous reactions, Catalog of Selected Documents in Psychology, Vol.9, No.2, 23-24, 1979.

[55] D. A. DeSteno, P. Valdesolo, P., M. Y. Bartlett. Jealousy and the threatened self: Getting to the heart of the green-eyed monster, Journal of Personality and Social Psychology, Vo.91, No.4, 626-641, 2006.

[56] J. Wittkowski. The construction of the multidimensional orientation toward dying and death inventory (MODDI-F), Death Studies, Vol.25, No., 479-495, 2001.

[57] D. Watson, L. A. Clark. The PANAS-X: Preliminary Manual for the Positive and Negative Affect Schedule-Expanded
Form. Unpublished manuscript, Southern Methodist University, Dallas, Texas, 1991.

[58] M. J. Landau, M. Johns, J. Greenberg, T. Pyszczynski, A. Martens, J. Goldenberg, S. Solomon. A function of form: Effects of mortality salience on structuring the social world, Journal of Personality and Social Psychology, Vol.87, No.2, 190-210, 2004.

[59] B. K. Gehl, D. Watson. Defining the Structure of Jealousy through Factor Analysis. Poster presented at the Society for Personality and Social Psychology annual meeting, Los Angeles, 2003

[60] J. Arndt, J. Greenberg, A. Cook. Mortality salience and the spreading activation of worldview-relevant constructs: Exploring the cognitive architecture of terror management, Journal of Experimental Psychology: General, Vol.131, 307-324, No.3, 2002.

[61] J. Arndt, A. Cook, C. Routledge. The blueprint of terror management: Understanding the cognitive architecture of psychological defense against the awareness of death. In J. Greenberg, S. L. Koole, T. Pyszczynski, Handbook of Experimental Existential Psychology, Guilford, New York, 2004.

[62] C. R. Cox, D. P. Cooper, M. Vess, J. Arndt., J. L. Goldenberg, C. Routledge. Bronze is beautiful but pale can be pretty: The effects of appearance standards and mortality salience on tanning outcomes, Health Psychology, Vol.28, No.6, 746-752, 2009.

[63] B. P. Buunk, R. B. Hupka. Cross-cultural differences in the elicitation of sexual jealousy, Journal of Sex Research, Vol.23, No.1, 12-22, 1987.

[64] L. LeMoncheck. Loose Women, Lecherous Men: A Feminist Philosophy of Sex, Oxford University Press, Oxford, 1997.

[65] E. Harmon-Jones, C. K. Peterson, C. R. Harris. Jealousy: Novel methods and neural correlates, Emotion, Vol.9, No.1, 113-117, 2009.

[66] M. J. Landau, J. L. Goldenberg, J. Greenberg, O. Gillath, S. Solomon, C. Cox, A. Martens, T. Pyszczynski. The siren's call: Terror management and the threat of men's sexual attraction to women, Journal of Personality and Social Psychology, Vol.90, No.1, 129-146, 2006.

[67] C. R. Harris. Factors associated with jealousy over real and imagined infidelity: An examination of the social-cognitive and evolutionary psychology perspectives, Psychology of Women Quarterly, Vol.27, No.4, 319-329, 2003.

[68] N. Frijda. The Emotions: Studies in Emotion and Social Interaction. Cambridge, New York, 1986.

[69] R. S. Lazarus. Emotion and Adaptation, Oxford, New York, 1991.

[70] A. Ortony, G. L. Clore, A. Collins. The Cognitive Structure of Emotions. Cambridge University Press, Cambridge, 1988.

[71] C. R. Harris. The evolution of jealousy, American Scientist, Vol.92, No.1, 62-71, 2004.

[72] T. K. Shackelford, M. Voracek, D. P. Schmitt, D. M. Buss, V. A. Weekes-Shackelford, R. L. Michaiski. Romantic jealousy in early adulthood and in later life, Human Nature, Vol.15, No.3, 283-300, 2004. 
[73] G. L. White. A model of romantic jealousy, Motivation \& Emotion, Vol.5, No.4, 295-310, 1981.

[74] S. Kosloff, J. Greenberg, D. Sullivan, D. Weise. Of trophies and pillars: Exploring the terror management functions of short-term and long-term relationship partners, Personality and Social Psychology Bulletin, Vol.36, No.8, 1037-1051, 2010.
[75] J. Goldenberg, C. R. Cox, T. Pyszczynski, J. Greenberg, S. Solomon. Understanding human ambivalence about sex: The effects of stripping sex of meaning, Journal of Sex Research, Vol.39, No.4, 310-320, 2002. 